Running head: A bilingual advantage in memory capacity

This is a pre-print of an article published in International Journal of Bilingualism. The final authenticated version is available online at:

https://journals.sagepub.com/doi/abs/10.1177/1367006920965714

Please cite the published paper as:

Durand López, E. M. (2021). A bilingual advantage in memory capacity: Assessing the roles of proficiency, number of languages acquired and age of acquisition. International Journal of Bilingualism, 25(3), 606-621. https://doi.org/10.1177/1367006920965714

A bilingual advantage in memory capacity: Assessing the roles of proficiency, number of languages acquired and age of acquisition

Ezequiel M. Durand López

Rutgers University

Address for correspondence

Any correspondence concerning this article should be addressed to Ezequiel M. Durand López, Rutgers University, 15 Seminary Place-West, New Brunswick, NJ 08901, USA. 
Email address: durand.ezequiel@rutgers.edu

\begin{abstract}
Aims and objectives

This study examines whether different types of bilingualism modulate memory capacity differently. More specifically, the study assesses the effects of age of acquisition, number of languages acquired and proficiency in the L2 on phonological short-term memory, visuospatial memory and semantic memory.
\end{abstract}

\title{
Design
}

Memory capacity was measured by means of three tasks: digit span task (phonological short-term memory), Corsi block task (visuospatial memory) and word span task (semantic memory). Participants were divided into five groups based on the number of languages acquired, age of acquisition and proficiency: monolinguals, intermediate L2 learners, advanced L2 learners, simultaneous bilinguals and multilinguals.

\section{Data and analysis}

Analyses of variance were used to analyze participants' scores for each of the memory tasks.

\section{Findings and conclusions}


For the word span task, no significant differences were found among the groups, which supports the notion that semantic memory is language independent. Furthermore, intermediate and advanced L2 learners and multilinguals presented significantly higher phonological short-term memory spans compared to simultaneous bilinguals. Finally, intermediate L2 learners and multilinguals significantly outperformed monolinguals on visuospatial memory spans. Results suggest that L2 acquisition might strengthen both visuospatial and phonological short-term memory, which in turn tend to improve as L2 proficiency increases.

\section{Originality}

While previous studies have provided evidence of a bilingual advantage in memory capacity, these studies have generally grouped different types of bilinguals together (e.g., L2 leaners and heritage speakers). This study takes a step forward by examining differences on memory capacity across different types of bilinguals and in comparison to their monolingual peers in order to better understand the cognitive effects of bilingualism.

\section{Significance and Implications}

When considering age of acquisition, number of languages acquired and proficiency as grouping factors, different effects of bilingualism on memory capacity can be observed. Future studies on this matter should include bilingual participants that are comparable with regard to the aforementioned variables. 
Keywords: bilingual advantage hypothesis, bilingualism, heritage bilingualism, multilingualism, phonological short-term memory, semantic memory, visuospatial memory

A bilingual advantage in memory capacity: Assessing the roles of proficiency, number of languages acquired and age of acquisition

Bilingualism and multilingualism are the norm and not the exception nowadays (Harris \& McGhee-Nelson, 1992), as over half of the world's population is estimated to be bilingual (Grosjean, 2010). Therefore, it is not surprising that the study of cognitive and neural bases of language acquisition by bilinguals and multilinguals has grown considerably in the last decades. However, there are still many caveats regarding whether bilingualism, defined as the ability to speak two languages regardless of the age of language acquisition (AoA), implies any cognitive or linguistic advantage over monolingual individuals, and empirical evidence to date has led to contradictory results. Several studies have shown that bilinguals possess a smaller vocabulary in each of their languages compared to monolinguals, both in early childhood (Bialystok, Luk, Peets \& Yang, 2010; Mahon \& Crutchley, 2006) and adulthood (Portocarrero, Burright \& Donovick, 2007), they are slower and less accurate in picture naming tasks (Gollan, Montoya, Fennema-Notestine \& Morris, 2005; Ivanova \& Costa, 2008; Kaushanskaya \& Marian, 2007), have lower semantic fluency (Portocarrero et al., 2007) and present longer articulatory durations in first language (L1) speech production (Sadat, Martin, Alario \& 
Costa, 2012).

On the other hand, other studies have found several cognitive and linguistic advantages of bilingualism. Regarding cognitive advantages, studies found that bilinguals are faster in conflict resolution tasks which recruit a high amount of monitoring resources (Costa, Hernández, Costa-Faidella \& Sebastián-Gallés, 2009; Kovács \& Mehler, 2009), have an enhanced attentional control capacity (Comishen, Bialystok \& Adler, 2019; Soveri, Laine, Hämäläinen \& Hugdahl, 2011), exhibit better episodic memory than their monolingual peers in late adulthood (Schroeder \& Marian, 2012), respond faster and have smaller conflict effects on attentional network tasks (Costa, Hernández \& Sebastián-Gallés, 2008) and show signs of dementia four years later than monolinguals (Bialystok, Craik \& Freedman, 2007). With regard to linguistic advantages, bilinguals can discriminate languages based on visual cues (Sebastián-Gallés, Albareda-Castellot, Weikum \& Werker, 2012) and they outperform monolinguals in novel word learning tasks (Kaushanskaya \& Marian, 2009).

The bilingual advantage in certain cognitive functions has been attributed to the fact that bilinguals need to control two linguistic systems, which entails additional computations to constantly inhibit one of their languages (Soveri et al., 2011). Working memory (WM) is another cognitive domain thought to be affected by the bilingual experience, as it involves executive control functions which are necessary in order to inhibit the other, unintended language or switch from one language to the other (Bialystok, Craik \& Luk, 2008, 2012).

Furthermore, the linguistic automatization hypothesis (Vejnović, Milin \& Zdravkovi, 2010) claims that a higher degree of proficiency in the second language (L2) may trigger a series of cognitive mechanisms that could ultimately strengthen WM. More specifically, 
this proposal states that high L2 proficiency enables greater processing automatization in the L2, which leads to lower cognitive processing costs. This is consistent with previous studies, as L2 automatization has been found in the way L2 learners process morphology (e.g., Gürel \& Uygun, 2013, which found a native-like pattern of morphological processing due to higher L2 automatization), or in the use of distinct memory systems (e.g., Ullman, 2001, 2015, which concluded that novice L2 learners rely on declarative memory, while highly proficient L2 speakers rely wholly on procedural memory, a memory system also used by native speakers, due to increased automatization of the L2). According to the linguistic automatization hypothesis, this efficiency in processing requires fewer cognitive resources to be employed. In turn, this allows for a larger portion of these resources to be available, which could cause proficient L2 learners to show superior memory spans.

However, many questions still remain unanswered regarding the bilingual advantage hypothesis. First, it is not clear whether bilingualism affects the development and functioning of memory in general and WM in particular (Bialystok, 2009; Blom, Küntay, Messer, Verhagen \& Leseman, 2014; Tse \& Altarriba, 2012) and whether the trilingual advantage or disadvantage differs from that of the bilingual speaker (Bialystok \& Craik, 2010). Moreover, many linguistic variables such as proficiency, number of languages acquired and AoA have not been sufficiently addressed as potential determining factors of cognitive abilities. Despite the growing number of studies on the relation between bilingualism and memory (in children: e.g., Brito \& Barr, 2012; Hoff \& McKay, 2005; Kaushanskaya, Gross \& Buac, 2014; Kormi-Nouri et al., 2008; in adults: e.g., Bialystok et al., 2008; Wodniecka, Craik, Luo \& Bialystok, 2010), to the best of my knowledge, few studies to date have compared memory spans of adult monolinguals, multilinguals and 
bilinguals with varying degrees of L2 proficiency and who acquired more than one language at different ages. These factors have an important impact on both cognition (Abutalebi et al., 2013; Blom et al., 2014; Ojima, Nakata \& Kakigi, 2005; Tse \& Altarriba, 2012) and language processing (Sagarra \& Herschensohn, 2010; Uygun \& Gürel, 2016), and their consideration in empirical studies is of utmost importance in order to avoid erroneous generalizations regarding the cognitive functioning of the bilingual mind. In the case of the number of languages acquired, the storage (i.e., linguistic knowledge) and processing (i.e., language use) of an increasing number of linguistic systems may enhance executive function more than that of two languages. In addition, some studies testing the bilingual advantage hypothesis (e.g., Bialystok, Poarch, Luo \& Craik, 2014) include multilinguals in their bilingual participant pool, thus employing the term bilingual in a less restrictive manner, which may affect results. As mentioned above, both models and studies on bilingual memory have claimed that as proficiency increases, executive function improves (e.g., Bialystok \& Barac, 2012; Tse \& Altarriba, 2012; Vejnović et al., 2010). Lastly, and in connection with the previous variable, AoA may also be a factor modulating bilingual memory, as the amount of cognitive resources employed in processing two L1s (in the case of simultaneous bilinguals) may be different from those used in the processing of a L2.

Drawing on the existing literature on memory and bilingualism, the present study aims to explore possible variations in phonological, visuospatial and semantic memory capacity among monolinguals, intermediate L2 learners, advanced L2 learners, simultaneous bilinguals and multilinguals. More precisely, the study examined whether the acquisition of one or more languages before and after puberty has an influence on memory 
capacity and whether this capacity changes as linguistic proficiency increases.

\section{The role of memory in language acquisition}

The phonological loop is one of the most widely investigated components of the traditional WM model (Baddeley, 2010). It is conceptualized as a subsystem that stores verbal information and prevents its decay by continuously refreshing this information in a rehearsal loop. Many studies have shown that phonological short-term memory (PSTM) constitutes a potentially important source of individual differences in linguistic processing in both L1 (for a comprehensive review, see Gathercole \& Baddeley, 1993) and L2 acquisition (Baddeley, Gathercole \& Papagno, 1998; Gathercole \& Thorn, 1998; Harrington \& Sawyer, 1992; Papagno \& Vallar, 1992, 1995; Papagno, Valentine \& Baddeley, 1991; Paradis, 2011). Other studies have found that PSTM aids vocabulary acquisition in both children (Gathercole, 1995; Service, 1992; Service \& Kohonen, 1995) and adults (Atkins \& Baddeley, 1998; Baddeley, Papagno \& Vallar, 1988; Papagno \& Vallar, 1992). Also, previous studies suggest that tasks entailing the use of this type of memory, as well as the ability to repeat words in an unfamiliar language, predict success in L2 acquisition (Ardila, 2003; Ganschow, Sparks, Javrosky, Pohlman \& Bishop-Mabury, 1991; Paradis, 2011; Service, 1992).

However, there are still certain discrepancies among studies that have investigated a possible effect of bilingualism on PSTM. Papagno and Vallar (1995) used an auditory digit span task and a non-word repetition task to measure multilinguals' (i.e., individuals who spoke fluently at least three languages) and bilinguals’ PSTM capacity and they found that multilinguals had significantly higher verbal short-term memory spans than the bilinguals. Kormos and Sáfár (2008) found a significant correlation between PSTM capacity 
(measured through a non-word repetition task) and proficiency test results of a group of pre-intermediate Hungarian L2 learners of English, but the same pattern of results was not replicated for those students who had an elementary proficiency level in English. These findings seem to indicate that PSTM might be a good predictor of success in L2 acquisition at least in some proficiency groups. Mathur, Tiwari and Bellur (2010), on the other hand, focused their study on the relation between bilingualism, memory and age by comparing the performance of bilingual children aged 5-7.11 and 8-10.11 years old in several memory and vocabulary tasks. Although both groups obtained similar results in the vocabulary task, older bilingual children reached higher scores in three memory tasks (i.e., non-word repetition task, digit span task and word span task). The authors concluded that memory improves with age and that it is crucial for early vocabulary development in bilingual children. Nevertheless, it is important to note that none of the studies cited above tested different types of bilinguals based on their AoA or their degree of L2 proficiency.

The visuospatial sketchpad is another subsystem of Baddeley's WM model. It is responsible for temporarily storing and integrating spatial, visual and arguably kinesthetic information into a unified representation (Baddeley, 2010) and it is thought to be involved in reading tasks, as well as in tasks requiring eye movements (Baddeley, 2003). Contrary to the phonological loop, the relation between bilingualism and visuospatial memory has received less attention. Bialystok et al. (2008) assessed young and older monolinguals' and bilinguals' WM capacity, lexical retrieval and executive control. To measure visuospatial memory, the authors administered the Corsi block task and the self-ordered pointing task. Although there were no differences between groups in the self-ordered pointing task, younger bilinguals outperformed their monolingual peers in the Corsi block task. This 
finding seems to suggest that bilingualism might have an impact on certain aspects of visuospatial memory capacity. Similarly, Luo, Craik, Moreno and Bialystok (2013) tested verbal and visuospatial memory capacity in older and younger bilingual and monolingual adult speakers in order to explore whether these cognitive functions change across the lifespan. The results of their study showed that regardless of the age group, bilinguals outperformed monolinguals in the Corsi block task, while monolinguals slightly outperformed their bilingual peers on verbal WM tasks (a word span task and an alpha span task). The results also illustrate the fact that the bilingual status does not prevent age-related decline in WM. Another study that attempted to investigate bilinguals' allegedly enhanced visuospatial memory with a more ecologically valid method was one conducted by Kerrigan, Thomas, Bright and Filippi (2017). The researchers tested the visuospatial memory capacity of L2 learners of English of different L1s by means of two tasks, the change blindness task and the Corsi block task. The results of their study revealed that the bilingual group was significantly faster and more accurate than the monolingual group in both tasks. Although the authors are unsure whether these benefits are caused by an enhancement of independent mechanisms of language processing and visuospatial memory, the results confirm prior findings on a bilingual advantage in visuospatial memory.

Finally, semantic memory entails the knowledge that people acquire of the meaning of words, properties of objects and how they are structured and facts about the world that surrounds them (Haberlandt, 1998, p. 90). This type of memory is not language specific and does not depend on context (Vargha-Khadem et al., 1997). Rather, it is comprised of concepts organized in greater units or semantic networks. The specificity of these networks is dependent on several factors, such as chronological age. As a person grows up, semantic 
categories become more sophisticated and, generally, less vague.

Theoretical accounts suggest that simultaneous bilinguals possess a smaller repertoire of words and weaker access to the lexical items of their languages (e.g., Bialystok \& Craik, 2010; Hoff \& McKay, 2005; Portocarrero et al., 2007). For instance, Hoff and McKay (2005) argued that simultaneous bilingual children have less exposure to each of their languages compared to their monolingual peers, which results in differences in their semantic and phonological skills. Other studies showed that the effects of L2 acquisition on semantic memory can be explained by a general language theory. This proposal, known as the Revised Hierarchical Model (Kroll \& Stewart, 1994; Kroll, Van Hell, Tokowicz \& Green, 2010), maintains that there is a distinction between a lexical level-which entails two lexicons, one for the L1 and one for the L2- and a conceptual level, where meaning of facts and lexemes are stored (i.e., semantic memory). The lexical relations between levels of representation are asymmetrical, as the lexical level of the L2 is more strongly linked to the L1 than the opposite. According to this account, the L1 has privileged access to meaning, while the $\mathrm{L} 2$ requires mediation through the $\mathrm{L} 1$ lexical translation equivalents until the bilingual speaker acquires sufficient skills in the L2 in order to access meaning directly. Thus, L2 to L1 translation does not require semantic access, since this process can be performed lexically, whereas L1 to L2 translation needs to be semantically mediated due to the strong L1 link to semantic memory (Kroll \& Stewart, 1994; Kroll, Van Hell, Tokowicz \& Green, 2010).

To sum up, in the last decades there has been an increasing interest in the role of bilingualism in certain cognitive functions such as memory. However, the way in which the linguistic characteristics of bilingual speakers (e.g., AoA, number of languages acquired, 
L2 proficiency) influence this capacity has not been fully addressed in previous research. The present study aims to shed some light in this regard by examining the effect of type of bilingualism and L2 proficiency on PSTM, visuospatial and semantic memory with the ultimate goal to elucidate whether there is a bilingual advantage in memory function. Drawing on previous empirical studies, I predict that highly proficient sequential bilinguals and multilingual speakers will have higher PSTM and visuospatial memory spans than their monolingual and simultaneous bilingual peers. This is because (a) achieving a high proficiency in the L2 is a daunting task that, despite consuming a pronounced amount of cognitive resources over time, also leads to enhancement of executive control ability, which is closely linked to WM capacity (e.g., Bialystok, 2015; Vejnović et al., 2010), (b) monolinguals and simultaneous bilinguals, as they have not acquired an L2 and therefore have not had any experience dealing with the complex cognitive task of L2 acquisition and processing, they should not present any enhancement on the storage component of these two subsystems of WM compared to the other groups. I also predict there will not be any difference in semantic memory spans as a function of type of bilingualism as said memory seems to be language independent.

\section{Method}

\section{Participants}

Eighty-eight university students participated in the present study. All of them majored in areas other than Psychology or Linguistics in order to avoid confounding results, as students pursuing a degree in these areas are often familiar with the tests used in this study. Two participants were excluded because they did not understand the instructions in two of the three tasks and consequently failed to respond accurately. After these 
exclusions, the final sample included 86 participants. Fifty-four of them were females and 32 males, aged between 19 and 41 years old $(M=25.27, S D=5.37)$. Seventeen were monolinguals, 35 were L2 learners that had intermediate $(n=18)$ or advanced $(n=17)$ proficiency in the L2, 17 were simultaneous bilinguals and 17 were multilinguals. Both of the aforementioned recruitment variables (i.e., age group and educational background) were carefully considered, as neuroimaging studies have found that WM spans tend to be significantly lower as a person ages, especially in individuals with lower education (e.g., Archer, Lee, Qiu \& Chen, 2018).

Monolingual participants were all native speakers of Spanish who were born and raised in Argentina and were chosen based on two criteria: (1) they could not have spent more than one month in a foreign language country and (2) they could not have received instruction in the L2 outside of mandatory courses in Argentina (middle and high school). A language background questionnaire showed that the degree of proficiency in their L2, if any, was always below the threshold level (B1, equivalent to the intermediate-low level in ACTFL; Tschirner \& Bärenfänger, 2012). Self-reported scores for speaking, reading and listening comprehension below four points out of ten were interpreted as below the B1 level. According to the Common European Framework of Reference for Languages (2001), a speaker that has reached this level is able to hold a discussion, give an opinion, or explain a project or idea simply.

Simultaneous bilinguals, on the other hand, acquired English and Spanish at the same time from birth, and received education only in their dominant language (i.e., English). Intermediate and advanced L2 learners acquired English or Spanish as a L1 and the other language as a L2. They attended a monolingual school and acquired the L2 in a formal 
instruction context. The mean AoA of L2 for intermediate L2 learners was 15.12 years of age $(S D=2.22)$ and for advanced L2 learners it was 15.18 years of age $(S D=1.13)$. L2 learners reached different degrees of proficiency in the L2. While intermediates had a B1B2 level (equivalent to intermediate-mid up to advanced-mid in ACTFL; Tschirner \& Bärenfänger, 2012), advanced L2 learners reached a C1-C2 level (equivalent to advancedhigh up to distinguished in ACTFL; Tschirner \& Bärenfänger, 2012). Their self-reported proficiency scores in the three aforementioned L2 skills served the purpose of placing L2 learners into the intermediate or advanced proficiency group (for those participants who did not have an official certificate of L2 proficiency). More specifically, L2 learners with four to eight points in each L2 skill were considered intermediates and those with nine or ten points were considered advanced L2 learners. In case a participant had two of the three skills within a proficiency range, but a third skill below or above the cut-off point of that proficiency level, the mean of the three scores was considered. Finally, neither simultaneous bilinguals nor L2 learners reported speaking a third language.

Multilinguals, on the other hand, had acquired two languages from birth (i.e., they were simultaneous bilinguals only at a given point in time) and they learned one or more L2(s) after puberty (mean AoA of their first L2 $=15.14, S D=4.35$; mean AoA of their second L2, if applicable $=18.14, S D=3.24)$, reaching an advanced level $(\mathrm{C} 1-\mathrm{C} 2)$ in both L2s. Multilingual participants spoke three $(n=10)$ or four $(n=7)$ of the following languages: Spanish, English, German, French, Russian and Basque, and Spanish was one of the L1s of all multilingual participants. A specific language combination was not sought, as the degree of grammatical overlap across languages does not seem to modulate the amount of executive control enhancement (Barac \& Bialystok, 2012). 
None of the participants reported speaking more than one variety of any of their languages. Considering the bidialectal status of a participant may have important consequences for studies on the bilingual advantage hypothesis. More specifically, if each particular variety of a language is considered as a language itself given a certain degree of cross-linguistic overlap, then a speaker of both varieties would be considered bilingual. Therefore, they could be included in a pool of participants being recruited in a study exploring potential bilingual advantages, thus affecting the results of the study. Finally, to be included in the study, all participants should have used their languages constantly in the five years prior to the study.

\section{Materials and Procedure}

Participants signed a consent form, filled out a language background questionnaire and performed three memory tasks (the digit span task, the Corsi block task and the word span task, in this order) during a single 45-minute session. Participants received instructions for each task in English, with the exception of the monolingual group, in which case all instructions were given in Spanish.

Language background questionnaire. Participants completed the Language Experience and Proficiency Questionnaire (LEAP-Q; Marian, Blumenfeld \& Kaushanskaya, 2007) which is comprised of three main sections. The first section contains three general, autobiographical questions (gender, age, last name), the second section includes nine questions regarding the linguistic and cultural history of the participants, while the third section focuses on each of the languages the participant speaks. Some questions demand factual answers, whereas others are based on participants' selfperception regarding their dominance of certain aspects of the languages they have 
acquired. Furthermore, participants were asked to report if they possessed any international certificate in each of their L2s. While the vast majority of them had one, some others $(n=$ 8) did not. In order to assess the degree of proficiency in a specific L2 for the participants who had not obtained a proficiency certificate for their L2(s), the self-ratings they provided in the LEAP-Q were considered.

Digit span task (DST). To assess participants’ PSTM function, a computerized version of the DST forward was used, which requires the storage and retrieval of an increasing number of digits. Participants listened to a string of numbers that appeared one at a time. They then entered the string of digits in the order in which they were presented. The task started with a string of four random digits. If the participant recalled the digits correctly, the following trial would include one more digit (i.e., five). This procedure would continue up to 25 digits per trial. The digits appeared at a frequency of one per second and there was no time limit to recall the sequence. The task would end when the participants entered an error in any three consecutive strings of digits. The digit span was calculated as the highest number of digits that participants could accurately recall, with a maximum of 25 points.

Corsi block task. A computerized version of the Corsi block task (Corsi, 1972) was used as a measure of participants' visuospatial memory function. Participants saw an array of nine boxes or blocks scattered on the computer screen which light up one at a time. Participants then recalled them at the end of each trial by clicking on each box in the order in which they appeared. In the first string of blocks, only two out of the nine blocks lit up in a particular order, one at a time. The interval of lighting between each block was one second. As the participants accurately recalled the sequence in the same order as the blocks 
lit up, more blocks were added to a new string, until all 9 blocks lit up in the last possible level. Once the depicted string ended, participants heard the word ready and they clicked on the same blocks that lit up in the same order within 10 seconds. The task ended when participants either (1) answered correctly the last level and, thus, obtained a Corsi span of 9, (2) answered incorrectly twice in two consecutive strings at any level of the task, or (3) answered incorrectly three non-consecutive strings.

Word span task (WST). A computerized version of the word span task was used to assess participants' semantic memory function. This task requires the immediate retrieval of real words in a language the participant speaks, either freely or in the same order of presentation. In the present study, the first variation of the task was chosen. Participants saw one word at a time every two seconds on the center of a computer screen and recalled as many words as they could. When the string of fifteen words ended, participants had three minutes to recall and write down as many words as they could. One point was allocated for every correct word recalled, giving a maximum score of fifteen points.

An English version of the task was administered to English L2 learners of Spanish and to simultaneous bilinguals, while monolinguals, Spanish L2 learners of English and multilinguals took a Spanish version of the task that was created for this study. This decision was made in order to avoid confounding results due to the very limited degree of English proficiency of some of the participants. For the English version, the list of words was taken from Yoo and Kaushanskaya's (2012) study. For viability reasons, the 5-word list (i.e., 5 monosyllabic words, 5 bisyllabic words and 5 trisyllabic words) was used only. In order to create the Spanish WST, the English words from Yoo and Kaushanskaya's (2012) WST that were similar in terms of lexical frequency and number of syllables were 
translated into Spanish. Lexical frequency of Spanish words in the Spanish version of the WST was measured using the LEXESP corpus (Sebastián-Gallés, Cuetos, Carreiras \& Martí-Antonin, 2000), whereas that of English words was measured using the Spoken BNC corpus (Love, Dembry, Hardie, Brezina \& McEnery, 2017). A t-test for independent samples showed that there were no significant differences in mean lexical frequency measures between Spanish $(M=41.13, S D=34.09)$ and English $(M=48.07, S D=60.43)$ words used in the respective WST versions, $t(28)=-.39, p=.701$. Finally, the order of presentation of words in each version was randomized across participants.

\section{Results}

Table 1 summarizes the descriptive statistics for the variables of the study, while Table 2 presents correlations between participants' scores in the three memory tasks, as well as partial correlations between the above variables after controlling for AoA.

Table 1

Descriptive statistics for the variables of the study

\begin{tabular}{lcccc}
\hline & Age (SD) & Digit span (SD) & Corsi span (SD) & Word span (SD) \\
\hline Mean & $25.27(5.37)$ & $6.64(1.23)$ & $6.07(1.19)$ & $8.86(1.59)$ \\
Monolinguals & $27.12(5.30)$ & $6.41(1.00)$ & $5.35(1.17)$ & $8.18(1.59)$ \\
Intermediate L2 learners & $22.60(4.08)$ & $6.70(0.92)$ & $6.55(1.43)$ & $8.65(1.14)$ \\
Advanced L2 learners & $27.53(4.96)$ & $7.40(1.30)$ & $5.88(1.11)$ & $9.53(1.30)$ \\
Simultaneous bilinguals & $22.47(5.08)$ & $5.65(0.93)$ & $6.00(0.61)$ & $9.12(2.03)$ \\
Multilinguals & $27.35(5.27)$ & $7.12(1.41)$ & $6.47(1.13)$ & $8.94(1.68)$ \\
Median & 24 & 7 & 6 & 9 \\
Skewness & 0.99 & 0.76 & 0.63 & -0.12 \\
Kurtosis & 0.70 & 1.61 & 0.45 & 0.73 \\
\hline
\end{tabular}

As can be seen, there was a moderate correlation between digit span and Corsi span $(r=.315, p=.003)$, as well as a weak albeit statistically significant correlation between Corsi span and word $\operatorname{span}(r=.264, p=.014)$, which both increased when AoA was considered in the analysis $(r=.401, p=.001$, and $r=.293, p=.015$ respectively). 


\section{Table 2}

Correlations between digit span, Corsi span and word span (in parenthesis correlations with AoA as control variable)

\begin{tabular}{lcc}
\hline & Digit span & Corsi span \\
\hline Digit span & - & - \\
Corsi span & $.315^{* *}\left(.401^{* *}\right)$ & - \\
Word span & $.099\left(.280^{*}\right)$ & $.264^{*}\left(.293^{*}\right)$ \\
\hline
\end{tabular}

In order to explore possible differences in memory function among monolinguals, intermediate L2 learners, advanced L2 learners, simultaneous bilinguals and multilinguals, a one-way ANOVA was carried out for each of the memory tasks. The results showed no main effect of group on word span, $F(4,82)=1.685, p=.161$, as well as a main effect of group on both digit span, $F(4,82)=6.033, p<.001$, and Corsi span, $F(4,82)=3.188, p=$ .016. Tukey's post hoc comparisons showed that the mean scores for digit span in all sequential bilingual groups were significantly higher than those of simultaneous bilinguals. More specifically, simultaneous bilinguals $(M=5.65)$ had statistically different digit spans than intermediate L2 learners $(M=6.70, p=.042, d=1.13)$, advanced L2 learners $(M=$ $7.40, p<.001, d=1.48)$ and multilinguals $(M=7.12, p=.002, d=1.23)$. However, there was no significant difference in digit spans between simultaneous bilinguals and monolinguals $(M=6.41, p=.277, d=.78)$. Moreover, there were no statistically significant differences among the sequential bilingual groups, as intermediate L2 learners performed similarly to advanced L2 learners $(p=.494, d=.54)$ and to multilinguals $(p=.788, d=$ $.35)$, and multilinguals performed similarly to advanced L2 learners ( $p=.991, d=.13)$. In addition, there were no statistically significant differences between monolinguals and 
intermediates $(p=.93, d=.30)$, advanced L2 learners $(p=.15, d=.77)$, multilinguals $(p=$ $.35, d=.57)$, or simultaneous bilinguals $(p=.277, d=.78)$.

Regarding Corsi span, Tukey post hoc comparisons showed that monolinguals $(M=$ 5.35) obtained significantly lower scores compared to intermediate L2 learners $(M=6.55, p$ $=.016, d=.90)$ and multilinguals $(M=6.47, p=.040, d=.97)$. However, monolinguals' Corsi spans were not significantly different than advanced L2 learners' $(M=5.88, p=.654$, $d=.46)$ or simultaneous bilinguals' $(M=6.00, p=.462, d=.69)$. Furthermore, there was no significant difference of Corsi spans between simultaneous versus sequential bilinguals. More specifically, simultaneous bilinguals' Corsi spans were not significantly different from those of intermediate L2 learners $(p=.585, d=.51)$, advanced L2 learners $(p=.998$, $d=.13$ ), or multilinguals ( $p=.746, d=.52)$. In addition, there were no significant differences of Corsi span between intermediate and advanced L2 learners $(p=.390, d=$ $.51)$, between intermediate L2 learners and multilinguals $(p=1.00, d=.06)$, or between multilinguals and advanced L2 learners $(p=.558, d=.52)$. See Figure 1 for the visual representation of these effects.

\section{Figure 1}

Plots for Digit Span, Corsi Span and Word Span in monolinguals, intermediate and advanced L2 learners, simultaneous bilinguals and multilinguals 

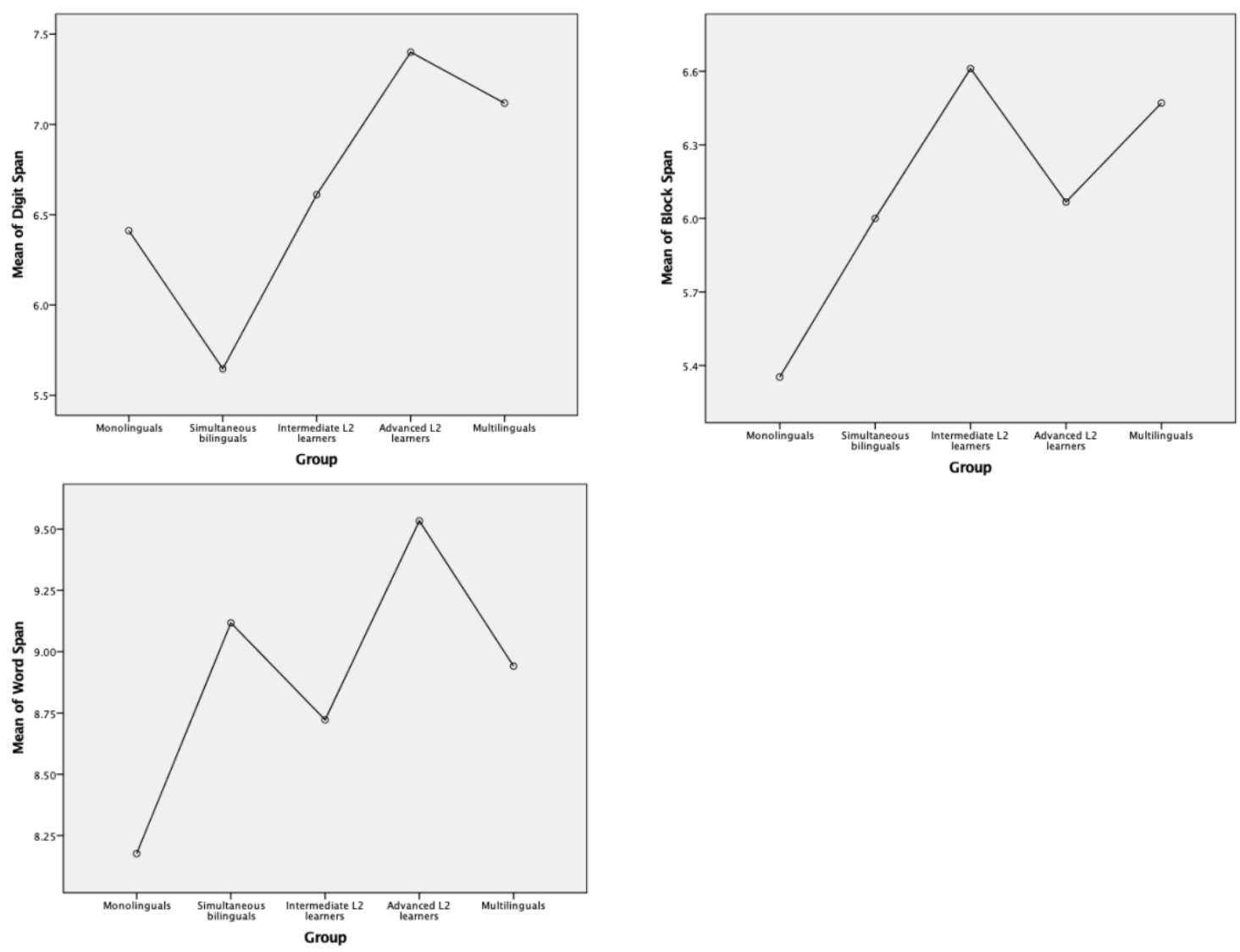

\section{Discussion}

The purpose of the present study was to examine whether bilingualism implies a cognitive advantage in terms of memory function and whether differences in this capacity are linked to a higher L2 proficiency, age of acquisition, or the number of languages acquired. Regarding semantic memory function, the results obtained did not show statistically significant differences between monolingual participants and those who had acquired two or more languages across the lifespan. This finding supports the idea that semantic memory is language independent. In other words, conceptual information, including the meaning of words and lexical items and the representation of facts about the world, seems to be unrelated to the number of languages acquired. Moreover, this finding is 
consistent with the Revised Hierarchical Model (Kroll \& Stewart, 1994; Kroll, Van Hell, Tokowicz \& Green, 2010), which posits that in the bilingual mind, lexicons associated with the L1 and L2 are connected to a common conceptual level that is not affected by the characteristics of the two individual lexicons.

With regard to PSTM, the results revealed that those individuals who acquired one language (i.e., intermediate and advanced L2 learners) or one or more languages (i.e., multilinguals) as an L2 had significantly higher PSTM compared to those individuals who acquired two languages at the same time (i.e., simultaneous bilinguals). While L2 learners received education in both of their languages, the simultaneous bilingual participants did not have the opportunity to attend a bilingual immersion school, thus receiving literacy skills and education only in one of their languages (i.e., the dominant language). A bilingual educational background as well as literacy in both languages may then allow for a progressive strenghthening of PSTM. In addition, some studies linked simultaneous bilinguals' smaller vocabulary spans with a smaller PSTM capacity. For instance, Hoff and McKay (2005) claim that where there are vocabulary differences there are also differences in phonological skills. Although this seems a convincing possibility, the present study did not aim at assessing participants' vocabulary sizes and therefore cannot establish a correlation between PSTM and vocabulary size.

Another plausible explanation for the differences observed in PSTM capacity between simultaneous bilinguals and the rest of the groups relies on the fact that L1 acquisition entails an unconscious process, while L2 learning, especially after puberty, often requires learning of explicit rules and monitoring the accuracy of the output (Krashen, 1981, 1982, 1985). These attentional demands could affect WM (Vejnović et al., 2010) and 
their functions, such as its storage component. It could be assumed that the progressive onset of sequential bilingualism (i.e., the progressive acquisition of a L2) allows for a strengthening of the executive function that results in a greater cognitive flexibility or automatization of L2 processing and this could potentially be manifested in tasks that rely heavily on PSTM, such as DST.

Among the groups that significantly outperformed simultaneous bilinguals on PSTM, advanced L2 learners and multilinguals were the groups that scored the highest on PSTM. Furthermore, the results revealed a tendency toward higher mean digit spans for intermediate L2 learners compared to their monolingual peers and a tendency for higher mean digit spans for both advanced L2 learners and multilinguals compared to L2 learners of intermediate proficiency and to monolinguals, although these differences did not reach statistical significance. Taken together, these results corroborate the multilingual advantage in PSTM (compared to monolinguals, intermediate L2ers and simultaneous bilinguals) and they are consistent with previous studies suggesting that multilinguals outperform monolinguals (Papagno \& Vallar, 1995) and intermediate L2 learners (Biedroń \& Szczepaniak, 2012) in PSTM tasks. These results can be interpreted in at least two ways. On the one hand, it could be hypothesized that prolonged exposure to an L2 and achieving higher L2 proficiency levels might enhance PSTM capacity. More specifically, L2 acquisition may provide a constant linguistic training that may force individuals who had otherwise acquired a fewer number of languages (often only their L1) to store linguistic information that is presented in the form of phonological forms. This constant training may stimulate the memory system over time, and could enhance PSTM, which is, as stated in the literature review, a type of memory particularly involved in language acquisition and 
processing. On the one hand, the early stages of L2 acquisition entail the consumption of many attentional resources (Hasegawa, Carpenter \& Just, 2002). It could be argued that in the case of highly proficient L2 learners a larger portion of cognitive resources are therefore available. While processing incoming information, advanced learners may thus make use of a more available memory system and this difference is shown in their memory spans.

Regarding visuospatial memory, bilinguals (more specifically, intermediate L2 learners as well as multilinguals) had significantly higher Corsi spans than their monolingual peers. This finding is in accordance with previous studies (Bialystok et al., 2008; Kerrigan et al., 2017; Luo et al., 2013) that showed that bilinguals outperform their monolingual peers in visuospatial memory tasks. A bilingual advantage in visuospatial memory and the sequential bilingual advantage in PSTM can be similarly interpreted, given that both the phonological loop and the visuospatial sketchpad are subsystems of the WM system. More specifically, assuming that a prolonged exposure to the L2 and higher L2 proficiency entail a greater availability of attentional resources at the WM level, this benefit may also affect WM's subcomponents such as the storage component of both the visuospatial sketpachpad and the phonological loop. Therefore, reaching an advanced proficiency level in the L2 may provide a similar stimulation for the said two types of memory, as they are interrelated within the WM system. This idea is also supported by a statistically significant positive correlation between digit spans and Corsi spans in the present study.

Finally, it is possible that the study had certain limitations which could have influenced the results. First, the sample size was relatively small for each of the five different subgroups. Future studies are encouraged to extend these findings with a larger 
pool of participants. Second, the tasks used to measure memory capacity tapped just a small part of the wide range of the memory system's functions. Future investigations should include tasks that assess working memory as a whole and not only its storage component. Third, certain sociodemographic factors, such as participants' profession, were not controlled for and that might have introduced certain noise to the results obtained. Furthermore, although the original goal was to recruit purely monolingual participants, this was not possible, as pure monolingualism is nowadays an infrequent phenomenon due to the mandatory learning of second languages during school years in Argentina. Finally, future work should try to examine in more depth whether and how these variables contribute (or not) to cognitive functions such as memory capacity by using a greater number of memory tasks that tap not only into short-term storage of WM, but also certain aspects of executive function.

\section{Conclusion}

This study was originally motivated by the abundance of experiments that have found bilingual advantages and disadvantages in certain cognitive domains, such as memory capacity, and whose bilingual participants have not been carefully split into different bilingual groups, according to their proficiency in the L2 or AoA of the L1 and L2. Therefore, the goal of this study was to assess the memory capacity of different groups of bilinguals, considering their AoA (i.e., simultaneous bilinguals vs. sequential bilinguals) and their different degrees of proficiency in the L2 (i.e., monolinguals, intermediate L2 learners, advanced L2 learners and multilinguals). The findings suggest that there is a bilingual advantage in visuospatial memory in intermediate L2 learners and multilinguals compared to their monolingual peers, on the one hand, and a bilingual advantage in PSTM 
in intermediate L2 learners, advanced L2 learners and multilinguals compared to their simultaneous bilingual peers, on the other hand. In addition, there seems to be no effect of managing two linguistic systems on semantic memory, which supports the notion that the conceptual level is independent of language.

Finally, if we consider the flexible definition of bilingualism by which this phenomenon entails the acquisition of two languages, regardless of their frequency of use, proficiency, AoA and availability of input, the findings of previous studies investigating cognitive effects of bilingualism could be significantly different than if bilingualism is defined in a more restrictive manner. The findings bring to light the need to consider the aforementioned variables when investigating the psycholinguistics of bilingualism.

\section{Acknowledgements}

I am grateful to Irini Mavrou for her valuable feedback and suggestions, which have improved this research and manuscript. I also thank Patrick Thane for his helpful comments, and the anonymous reviewers for their insightful observations.

\section{References}

Abutalebi, J., Della Rosa, P. A., Ding, G., Weekes, B., Costa, A., \& Green, D. W. (2013). Language proficiency modulates the engagement of cognitive control areas in multilinguals. Cortex, 49(3), 905-911.

Archer, J. A., Lee, A., Qiu, A., \& Chen, S. A. (2018). Working memory, age and education: a lifespan fMRI study. PloS one, 13(3), e0194878. 
Ardila, A. (2003). Language representation and working memory with bilinguals. Journal of Communication Disorders, 36, 233-240.

Atkins, P. W., \& Baddeley, A. D. (1998). Working memory and distributed vocabulary learning. Applied Psycholinguistics, 19(4), 537-552.

Baddeley, A. (2003). Working memory: Looking back and looking forward. Nature Reviews Neuroscience, 4(10), 829-839.

Baddeley, A. D. (2010). Working memory. Current Biology, 20(4), R136-R140.

Baddeley, A. D., Gathercole, S. E., \& Papagno, C. (1998). The phonological loop as a language learning device. Psychological Review, 105(1), 158-173.

Baddeley, A. D., Papagno, C., \& Vallar, G. (1988). When long-term learning depends on short-term storage. Journal of Memory and Language, 27(5), 586-595.

Barac, R., \& Bialystok, E. (2012). Bilingual effects on cognitive and linguistic development: Role of language, cultural background, and education. Child Development, 83, 413422.

Bialystok, E. (2009). Bilingualism: The good, the bad, and the indifferent. Bilingualism: Language and Cognition, 12(1), 3-11.

Bialystok, E. (2015). Bilingualism and the development of executive function: The role of attention. Child development perspectives, 9(2), 117-121.

Bialystok, E., \& Barac, R. (2012). Emerging bilingualism: Dissociating advantages for metalinguistic awareness and executive control. Cognition, 122(1), 67-73.

Bialystok, E., \& Craik, F. I. M. (2010). Cognitive and linguistic processing in the bilingual mind. Current Directions in Psychological Science, 19(1), 19-23. 
Bialystok, E., Craik, F. I. M., \& Freedman, M. (2007). Bilingualism as a protection against the onset of symptoms of dementia. Neuropsychologia, 45(2), 459-464.

Bialystok, E., Craik, F. I. M., \& Luk, G. (2008). Cognitive control and lexical access in younger and older bilinguals. Journal of Experimental Psychology: Learning, Memory and Cognition, 34(4), 859-873.

Bialystok, E., Craik, F. I., \& Luk, G. (2012). Bilingualism: consequences for mind and brain. Trends in cognitive sciences, 16(4), 240-250.

Bialystok, E., Luk, G., Peets, K. F., \& Yang, S. (2010). Receptive vocabulary differences in monolingual and bilingual children. Bilingualism: Language and Cognition, 13(4), $525-531$.

Bialystok, E., Poarch, G., Luo, L., \& Craik, F. I. (2014). Effects of bilingualism and aging on executive function and working memory. Psychology and aging, 29(3), 696.

Biedroń, A., \& Szczepaniak, A. (2012). Working memory and short-term memory abilities in accomplished multilinguals. The Modern Language Journal, 96(2), 290-306.

Blom, E., Küntay, A. C., Messer, M., Verhagen, J., \& Leseman, P. (2014). The benefits of being bilingual: Working memory in bilingual Turkish-Dutch children. Journal of experimental child psychology, 128, 105-119.

Brito, N., \& Barr, R. (2012). Influence of bilingualism on memory generalization during infancy. Developmental Science, 15(6), 812-816.

Comishen, K. J., Bialystok, E., \& Adler, S. A. (2019). The impact of bilingual environments on selective attention in infancy. Developmental science, 22, e12797. 
Council of Europe. Council for Cultural Co-operation. Education Committee. Modern Languages Division. (2001). Common European Framework of Reference for Languages: Learning, teaching, assessment. Cambridge University Press.

Corsi, P. (1972). Human memory and the medial temporal region of the brain. Unpublished Doctoral Dissertation, McGill University, Montreal.

Costa, A., Hernández, M., Costa-Faidella, J., \& Sebastián-Gallés, N. (2009). On the bilingual advantage in conflict processing: Now you see it, now you don't. Cognition, 113(2), 135-149.

Costa, A., Hernández, M., \& Sebastián-Gallés, N. (2008). Bilingualism aids conflict resolution: Evidence from the ANT task. Cognition, 106(1), 59-86.

Ganschow, L., Sparks, R. L., Javrosky, J., Pohlman, J., \& Bishop-Marbury, A. (1991). Identifying native language difficulties among foreign language learners in college: A “foreign” language learning disability? Journal of Learning Disabilities, 24(9), 530541.

Gathercole, S. E. (1995). Is nonword repetition a test of phonological memory or long-term knowledge? It all depends on the nonwords. Memory \& Cognition, 23(1), 83-94.

Gathercole, S. E., \& Baddeley, A. D. (1993). Phonological working memory: A critical building block for reading development and vocabulary acquisition? European Journal of Psychology of Education, 8(3), 259-272.

Gathercole, S. E., \& Thorn, A. S. (1998). Phonological short-term memory and foreign language learning. In A.F. Healy \& L.E. Bourne (Eds.), Foreign language learning (pp. 141 - 158). Hillsdale, NJ: Erlbaum. 
Gollan, T. H., Montoya, R. I., Fennema-Notestine, C., \& Morris, S. K. (2005). Bilingualism affects picture naming but not picture classification. Memory \& Cognition, 33(7), $1220-1234$.

Grosjean, F. (2010). Bilingual: Life and reality. Cambridge, MA: Harvard University Press.

Gürel, A., \& Uygun, S. (2013). Representation of multimorphemic words in the mental lexicon: Implications for second language acquisition of morphology. Proceedings of the 37th Annual Conference on Language Development, 122-133.

Haberlandt, K. (1998). Human Memory: Exploration and application. Boston, MA: Allyn \& Bacon.

Harrington, M., \& Sawyer, M. (1992). L2 working memory capacity and L2 reading skill. Studies in Second Language Acquisition, 14(1), 25-38.

Harris, R. J., \& McGhee-Nelson, E. M. (1992). Bilingualism: Not the exception any more. In R. J. Harris (Ed.), Cognitive processing in bilinguals (pp. 3-14). Amsterdam, Netherlands: Elsevier.

Hasegawa, M., Carpenter, P. A., \& Just, M. A. (2002). An fMRI study of bilingual sentence comprehension and workload. Neuroimage, 15(3), 647-660.

Hoff, E., \& McKay, J. (2005). Phonological memory skill in monolingual and bilingual 23month-olds. In J. Cohen, K. McAlister, K. Rolstad, \& J. MacSwan (Eds.), Proceedings of the 4th International Symposium on Bilingualism (pp. 1041-1044). Somerville, MA: Cascadilla Press.

Ivanova, I., \& Costa, A. (2008). Does bilingualism hamper lexical access in speech production? Acta Psychologica, 127(2), 277-288. 
Kaushanskaya, M., Gross, M., \& Buac, M. (2014). Effects of classroom bilingualism on taskshifting, verbal memory, and word learning in children. Developmental Science, 17(4), 564-583.

Kaushanskaya, M., \& Marian, V. (2007). Bilingual language processing and interference in bilinguals: Evidence from eye tracking and picture naming. Language Learning, 57(1), 119-163.

Kaushanskaya, M., \& Marian, V. (2009). The bilingual advantage in novel word learning. Psychonomic Bulletin \& Review, 16(4), 705-710.

Kerrigan, L., Thomas, M., Bright, P., \& Filippi, R. (2017). Evidence of an advantage in visuospatial memory for bilingual compared to monolingual speakers. Bilingualism, 20(3), 602-612.

Kormi-Nouri, R., Shojaei, R., Moniri, S., Gholami, A., Moradi, A., Akbari-Zardkhaneh, S., \& Nilsson, L. (2008). The effect of childhood bilingualism on episodic and semantic memory tasks. Scandinavian Journal of Psychology, 49(2), 93-109.

Kormos, J., \& Sáfár, A. (2008). Phonological short-term memory, working memory and foreign language performance in intensive language learning. Bilingualism: Language and Cognition, 11(2), 261-271.

Kovács, Á. M., \& Mehler, J. (2009). Cognitive gains in 7-month-old bilingual infants. Proceedings of the National Academy of Sciences, 106(16), 6556-6560.

Krashen, S. (1981). Second language acquisition and second language learning. Oxford, England: Pergamon.

Krashen, S. (1982). Principles and practice in second language acquisition. Oxford, England: Pergamon Press. 
Krashen, S. (1985). The input hypothesis: Issues and implications. London, England: Longman.

Kroll, J. F., \& Stewart, E. (1994). Category interference in translation and picture naming: Evidence for asymmetric connections between bilingual memory representations. Journal of Memory and Language, 33(2), 149-174.

Kroll, J. F., Van Hell, J. G., Tokowicz, N., \& Green, D. W. (2010). The Revised Hierarchical Model: A critical review and assessment. Bilingualism: Language and Cognition, 13(3), 373-381.

Love, R., Dembry, C., Hardie, A., Brezina, V., \& McEnery, T. (2017). The Spoken BNC2014: Designing and building a spoken corpus of everyday conversations. International Journal of Corpus Linguistics, 22(3), 319-344.

Luo, L., Craik, F. I. M., Moreno, S., \& Bialystok, E. (2013). Bilingualism interacts with domain in a working memory task: Evidence from aging. Psychology and Aging, 28(1), 28-34.

Mahon, M., \& Crutchley, A. (2006). Performance of typically-developing school-age children with English as an additional language on the British Picture Vocabulary Scales II. Child Language Teaching and Therapy, 22(3), 333-351.

Marian, V., Blumenfeld, H., \& Kaushanskaya, M. (2007). The Language Experience and Proficiency Questionnaire (LEAP-Q): Assessing language profiles in bilinguals and multilinguals. Journal of Speech, Language, and Hearing Research, 50(4), 940-967.

Mathur, M., Tiwari, S., \& Bellur, R. (2010). Bilingual vocabulary development and memory as a function of age. Journal of the All India Institute of Speech \& Hearing, 29(2), 153160. 
Ojima, S., Nakata, H., \& Kakigi, R. (2005). An ERP study of second language learning after childhood: Effects of proficiency. Journal of Cognitive Neuroscience, 17(8), 12121228.

Papagno, C., Valentine, T., \& Baddeley, A. D. (1991). Phonological short-term memory and foreign-language vocabulary learning. Journal of Memory and Language, 30(3), 331347.

Papagno, C., \& Vallar, G. (1992). Phonological short-term memory and the learning of novel words: The effect of phonological similarity and item length. The Quarterly Journal of Experimental Psychology Section A, 44(1), 47-67.

Papagno, C., \& Vallar, G. (1995). Verbal short-term memory and vocabulary learning in polyglots. The Quarterly Journal of Experimental Psychology Section A, 48(1), 98107.

Paradis, J. (2011). Individual differences in child English second language acquisition: Comparing child-internal and child-external factors. Linguistic approaches to bilingualism, 1(3), 213-237.

Portocarrero, J. S., Burright, R. G., \& Donovick, P. J. (2007). Vocabulary and verbal fluency of bilingual and monolingual college students. Archives of Clinical Neuropsychology, 22(3), 415-422.

Sadat, J., Martin, C. D., Alario, F. X., \& Costa, A. (2012). Characterizing the bilingual disadvantage in noun phrase production. Journal of Psycholinguistic Research, 41(3), $159-179$. 
Sagarra, N., \& Herschensohn, J. (2010). The role of proficiency and working memory in gender and number agreement processing in L1 and L2 Spanish. Lingua, 120(8), 20222039.

Schroeder, S. R., \& Marian, V. (2012). A bilingual advantage for episodic memory in older adults. Journal of Cognitive Psychology, 24(5), 591-601.

Sebastián-Gallés, N., Albareda-Castellot, B., Weikum, W. M., \& Werker, J. F. (2012). A bilingual advantage in visual language discrimination in infancy. Psychological Science, 23(9), 994-999.

Sebastián-Gallés, N., Cuetos, F., Carreiras, M., \& Martí-Antonin, M. (2000). LEXESP. Léxico informatizado del español. Barcelona, Spain: Publicacions de la Universitat de Barcelona.

Service, E. (1992). Phonology, working memory, and foreign-language learning. Quarterly Journal of Experimental Psychology, 45A, 21-50.

Service, E., \& Kohonen, V. (1995). Is the relation between phonological memory and foreign language learning accounted for by vocabulary acquisition? Applied Psycholinguistics, $16(2), 155-172$.

Soveri, A., Laine, M., Hämäläinen, H., \& Hugdahl, K. (2011). Bilingual advantage in attentional control: Evidence from the forced-attention dichotic listening paradigm. Bilingualism: Language and Cognition, 14(3), 371-378.

Tschirner, E., \& Bärenfänger, O. (2012). Assessing evidence of validity of assigning CEFR ratings to the ACTFL Oral Proficiency Interview (OPI) and the Oral Proficiency Interview by computer (OPIc). Technical Report 2012-US-PUB-1. Retrieved from 
https://www.languagetesting.com/pub/media/wysiwyg/research/OPIc-CEFR-StudyFinal-Report.pdf

Tse, C. S., \& Altarriba, J. (2012). The effects of first-and second-language proficiency on conflict resolution and goal maintenance in bilinguals: Evidence from reaction time distributional analyses in a Stroop task. Bilingualism: Language and Cognition, 15(3), 663-676.

Ullman, M. T. (2001). The neural basis of lexicon and grammar in first and second language: The declarative/procedural model. Bilingualism: Language and cognition, 4(2), 105122.

Ullman, M.T. (2015). The Declarative/Procedural Model: A Neurobiologically-Motivated Theory of First and Second Language. In B. VanPatten \& J. Williams (Eds.), Theories in Second Language Acquisition (pp. 135-158). New York, NY: Routledge.

Uygun, S., \& Gürel, A. (2016). Processing morphology in L2 Turkish. Second Language Acquisition of Turkish, 59, 251-279.

Vargha-Khadem, F., Gadian, D., Watkins, K., Connelly, A., Van Paesschen, W., \& Mishkin, M. (1997). Differential Effects of Early Hippocampal Pathology on Episodic and Semantic Memory. Science, 277(5324), 376-380.

Vejnović, D., Milin, P., \& Zdravković, S. (2010). Effects of proficiency and age of language acquisition on working memory performance in bilinguals. Psihologija, 43(3), 219232.

Wodniecka, S., Craik, F., Luo L., \& Bialystok, E. (2010). Does bilingualism help memory? Competing effects of verbal ability and executive control. International Journal of Bilingual Education and Bilingualism, 13(5), 575-595. 
Yoo, J., \& Kaushanskaya, M. (2012). Phonological memory in bilinguals and monolinguals. Memory \& Cognition, 40(8), 1314-1330. 